\title{
ESTUDO DO CICLO DE VIDA DO PEIXE-ESPADA \\ Trichiurus lepturus *
}

\author{
KESHIYU NAKATANI, YASUNOBU MATSUURA $\theta$ GOSUKE SATO \\ Instituto Oecanográfico Universidade de Săo Paulo \\ São Paulo, SP, Brasil
}

\section{SYNOPSIS}

Eggs and larvae of the cutlassfish. Trichiurus lepturus, were collected during the survey cruises of the project FINEP to determinate spawning areas and season. Six cruises were made from 1975 to 1977 in southern Brazil (23 $\left.{ }^{\circ} \mathrm{S} \cdot 29^{\circ} \mathrm{S}\right)$. Spawning occurred throughout the year, but intensivety in the cruise, May 1976 (autumn). The heavy spawning area was offshore region of Ilha Grande and of Ilha de Sta. Cata. rina. Mean temperature of the spawning area was $24.09^{\circ} \mathrm{C}$, ranging from 21.15 to $26.29^{\circ} \mathrm{C}$ and mean salinity was $35.31 \%$, ranging from 35.04 to $35.52 \%$. Catch data of cutlassfish fishery showed a gradual increase last several years in the two states: São Paulo and Santa Catarina.

\section{Introdução}

O conhecimento da biologia da fase inicial de vida dos peixes marinhos, é um importante subsídio para o estudo da biologia da pesca e dinâmica da população. Com relação aos estudos de ovos e larvas do peixe-essada (Trichiurus lepturus Linnaeus, 1758) no Brasil. existem apenas três trabalhos que reportam a ocorrência da espécie (Matsuura, 1971; Phonlor, 1973 e Weiss et al. 1976).

Portanto, o objetivo deste trabalho, é contribuir para o conhecimento da biologia do peixe-espada, com ênfase especial à distribuição dos ovos e larvas (áreas e épocas de desovas), e ttambém apresentar alguns aspectos da captura dos adultos desta espécie.

\section{Material e Método}

O material coletado foi proveniente de seis cruzeiros oceanográficos, realizados com o N/Oc. "Prof. W. Besnard" do Instituto Oceanográfico da Universidade de São Paulo, na região entre Cabo Frio (230 S) e sul do Cabo de Santa Marta Grande $\left(29^{\circ} \mathrm{S}\right.$ ), de novembro de 1975 a fevereiro de 1977 , num total de 812 estações oceanográficas.

A metodologia de coleta e o processamento dos dados foram baseados em Matsuura (1977) e a identificação dos ovos e larvas de T. lepturus, pelos trabalhos de Tsukahara $(1961 ; 1962)$. A área de estudo foi dividida em seis subáreas (Fig. 1) para estimar a abundância de ovos pelo método de Tanaka (1973). Os dados sobre

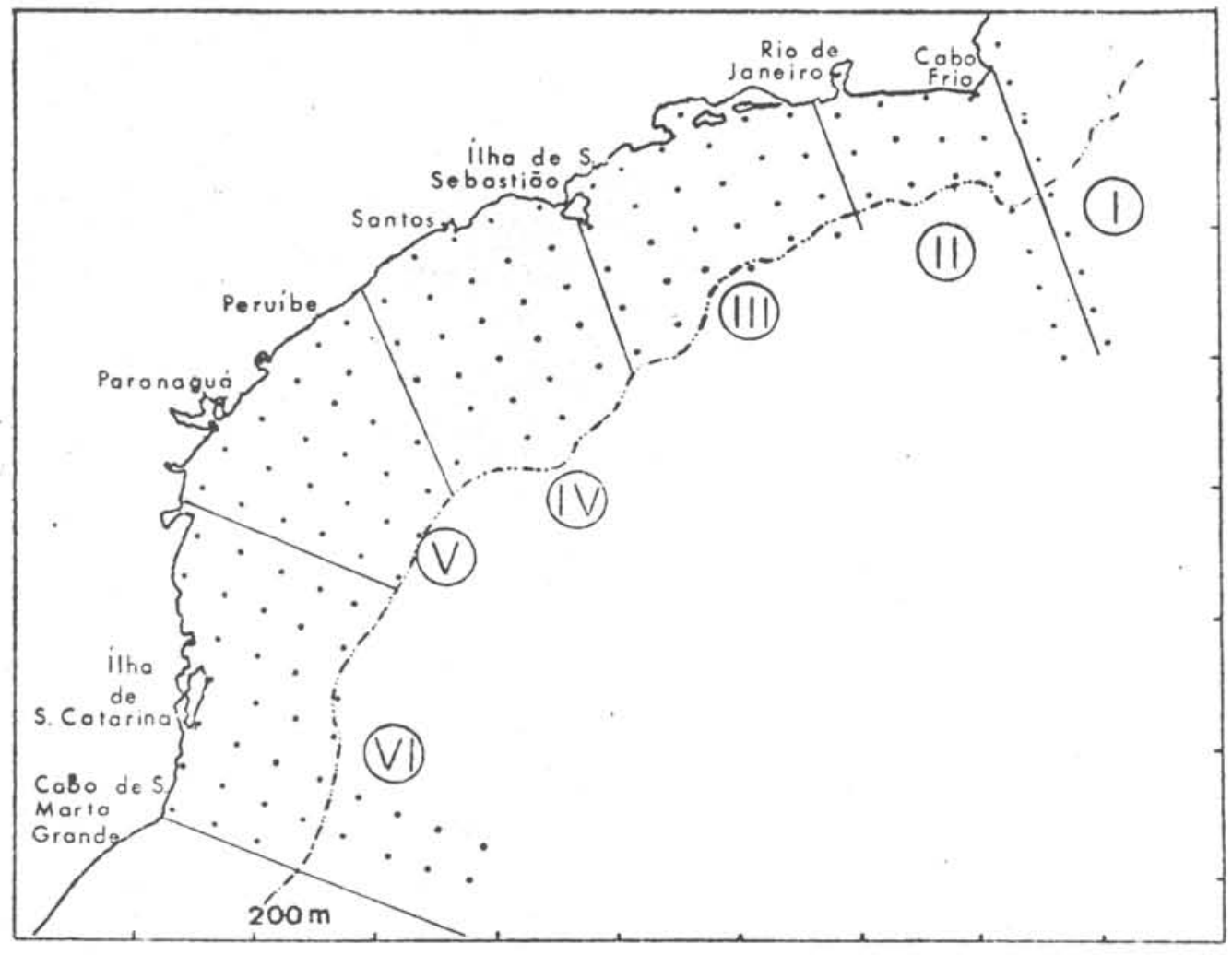

Fig. 1 - Estações de coletas realizadas durante os cruzeiros oceanográficos, e as divisões em subáreas para estimativa da abundância de ovos. 


\section{Distribuição de Ovos}

Na Figura 2 apresentamos as distribuições dos ovos, nos seis cruzeiros realizados. Analisando separadamente cada viagem, verificamos que no $1^{\circ}$ cruzeiro não houve aparecimento de grande concentrações de ovos, mas foram observadas ocorrências em toda a área pesquisada. No $2^{\mathrm{O}}$ cruzeiro, a maior concentração foi observada na região da Ilha de São Sebastião, enquanto que em outras regiões foram assinaladas apenas pequenas ou médias concentraçōes. No $3^{\circ}$ cruzeiro, apareceram três grandes concentrações de ovos, a primeira na região de Cabo Frio, a segunda próxima à llha Grande e a terceira entre a Itha de São Sebastião e Peruíbe. No $4^{\circ}$ cruzeiro, os ovos se distriburam principaimente em regiões de maior profundidade (isóbata de 100 a $200 \mathrm{~m}$ ), tendo sido assinalada grande ocorrência na região de Cabo Frio e Iguape. No $5^{\circ}$ cruzeiro, a maior desova foi na região de Cabo de Santa Marta Grande e na região da Iltha de São Sebastião. No 6 ? cruzeiro, foram assinaladas desovas na região da Ilha de São Sebastião e a mais ou menos 120 milhas náuticas fora da llha de São Francisco do Sul A temperatura média na área de desova se encontrava em torno de $24,09^{\circ} \mathrm{C}$, enquanto que a mínima, foi registrada no $4^{\circ}$ cruzeiro $\left(21,15^{\circ} \mathrm{C}\right)$ e a máxima, no $6^{\circ}$ cruzeiro $\left(26,29^{\circ} \mathrm{C}\right)$. Com relação à salinidade a média estava em torno de $35,31 \%$, sendo a mínima encontrada no 50 cruzeiro $(35,04 \%$ \%), e a máxima no 2 ? cruzeiro $\left(35,52^{\circ} \% \mathrm{oo}\right)$.
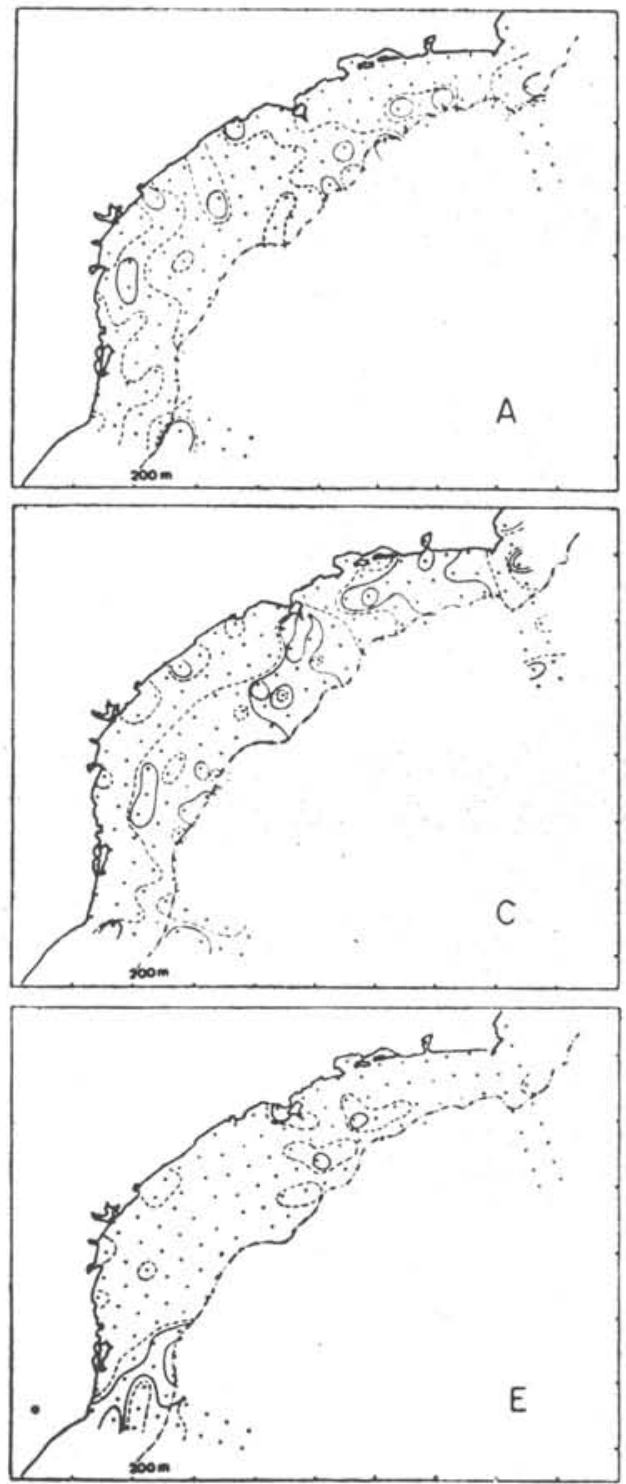
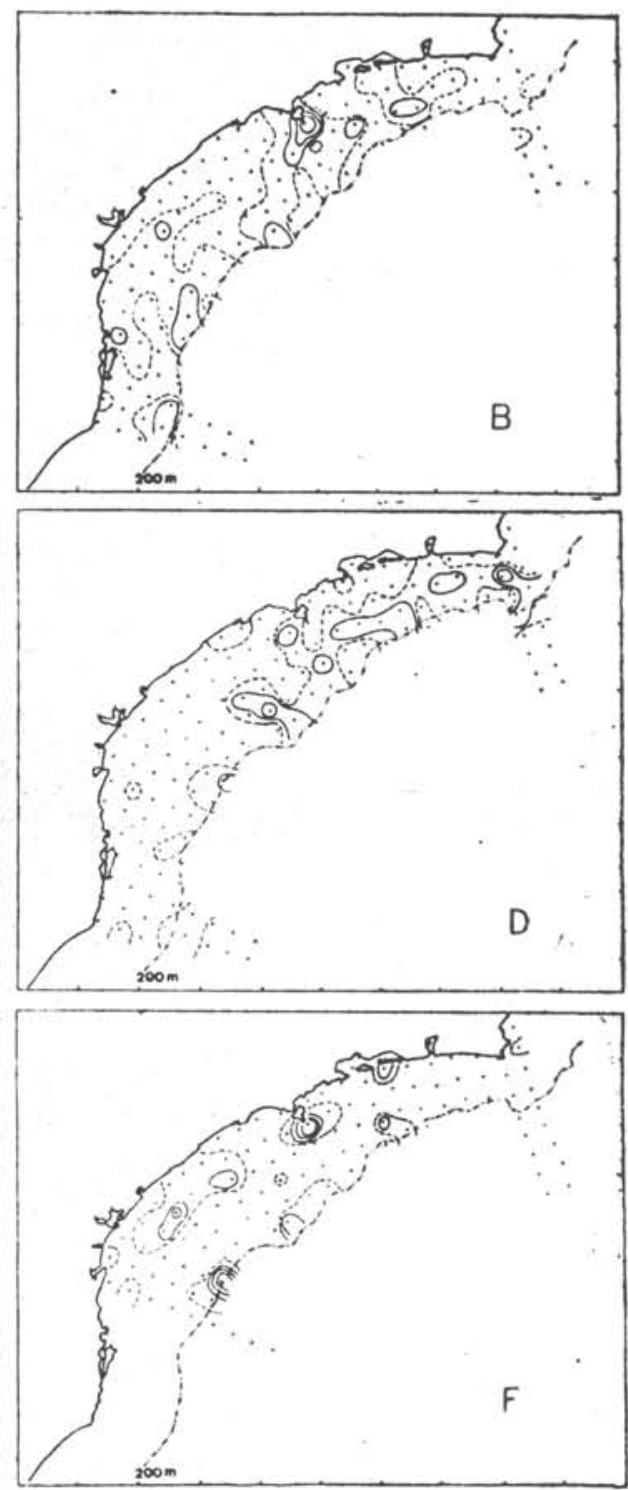

Fig. 2 - Distribuição dos ovos, A - I Cruzeiro (nov-dez/75), B - II Cruzeiro (jan/76), C - III Cruzeiro (mai/76), D - IV Cruzeiro (set-out/76), E - V Cruzeiro (dez/76), F - VI Cruzeiro (janfev/77). Aș isolinhas pontilhadas delimitam a ocorrência de $0,1 \mathrm{ovo} / \mathrm{m}^{2}$ até 1,0 ovos $/ \mathrm{m}^{2}$ e contínua delimitam a ocorrência de 1,1 até mais de 10,0 ovos $/ \mathrm{m}^{2}$. 


\section{Distribuiçilo de Larvas}

Na Figura 3, apresentamos a distribuição de larvas; nÆo foram assinaladas ocorréncias no $1^{\circ}$ e $5^{\circ}$ cruzeiros. Nos. $2^{\circ}, 4^{\circ}$ c $6^{\circ}$ cruzeiros, as ocorrências foram muito pequenas, quando comparadas com a ocorrência do 3 o cruzeiro, onde assinalamos grandes concentrações de larvas na região da Itha de São Sebastião e Cabo Frio.

\section{Estimativa da Abundância de Ovos}

Para o cálculo da abundância de ovos, segundo o método de Tanaka (1973), faz-se necessário conhecer o tempo (em dias) da incubação. No entretanto, analisando a correlaçao entre a hora da coleta o o estádio de desenvolvimento dos ovos. nato fol possivel determinar a hora da desova, isto porque o peixe-espada desova durante o dia todo. Por essa razấo. não calculamos o tempo de incubaçâo. Portanto, no cálculo da abundância de ovos, adotamos um valor provisório de 24 horas.

$\mathrm{Na}$ Tabela I apresentamos a estimativa da abundância re. lativa de ovos, para os seis cruzeiros, num total de $19.790 \times 10^{12}$ ovos depositados, sendo que a major ocorrência foi registrada nas subáreas de Ilha Grande e Ilha de Santa Catarina, com $4.188 \times 10^{12}$ e $3.979 \times 10^{12}$ ovos, respectivamente.

Na Figura 4 apresentamos o total de ovos por subárea, onde podemos verificar que a maior abundância ocorreu durante o
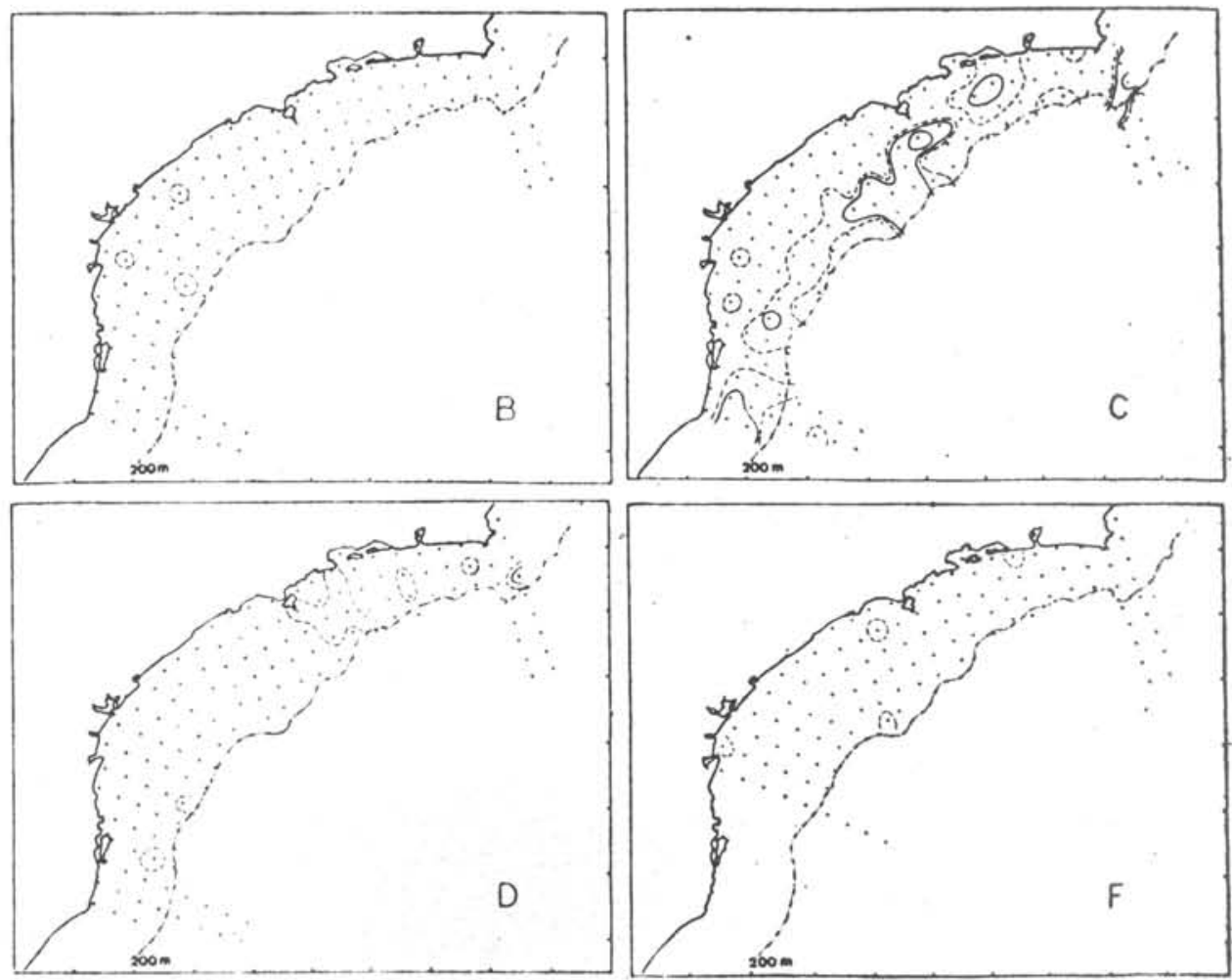

Fig. 3 - Distribuição de larvas, B-II Cruzeiro (jan/76), C-III Cruzeiro (mai/76), D-IV Cruzeiro (set-out/76), F-VI Cruzeiro (jan-fey/76). As isolinhas pontilhadas delimitam a ocorrência de 0,1 larva $/ \mathrm{m}^{2}$ até $1,0 \mathrm{larva} / \mathrm{m}^{2}$ e as contínuas delimitam a ocorrência de 1,1 larva/ $\mathrm{m}^{2}$ até mais de 10,0 larvas $/ \mathrm{m}^{2}$

Tabela I - Estimativa da abundância de ovos de T. Lepzurus *

\begin{tabular}{|r|c|c|c|c|c|c|c|}
\hline Aruzeiro & 18 & 29 & 39 & 48 & 58 & 69 & Total \\
\hline I & 0.635 & 0.080 & 1.554 & 0.660 & 0.094 & 0.037 & 3.060 \\
II & 0.125 & 0.064 & 1.027 & 0.580 & - & - & 1.796 \\
III & 0.334 & 0.796 & 1.238 & 0.615 & 0.274 & 0.931 & 4.188 \\
IV & 0.225 & 0.306 & 1.412 & 0.828 & 0.211 & 0.257 & 3.239 \\
V & 0.153 & 0.252 & 0.528 & 0.186 & 0.094 & 1.754 & 2.967 \\
VI & 0.719 & 0.568 & 1.031 & 0.147 & 1.346 & 0.168 & 3.979 \\
\hline Total & 2.191 & 2.066 & 6.790 & 3.016 & 2.019 & 3.147 & 19.229 \\
\hline
\end{tabular}

$3^{\circ}$ cruzeiro em toda a extensâo da área estudada, enquanto que, no 5 e e 60 cruzeiros, as maiores abundâncias foram verificadas na região sul (sub-áreas V e VI). Com relação à variação sazonal do total de ovos (Fig. 5), verificamos que no outono ocorreu maior abundância, enquanto que nas outras estaçōes do ano, as ocorréncias foram menores. 
Fig. 4- Abundância relativa de ovos depositados por cruzeiro e por subáreas.
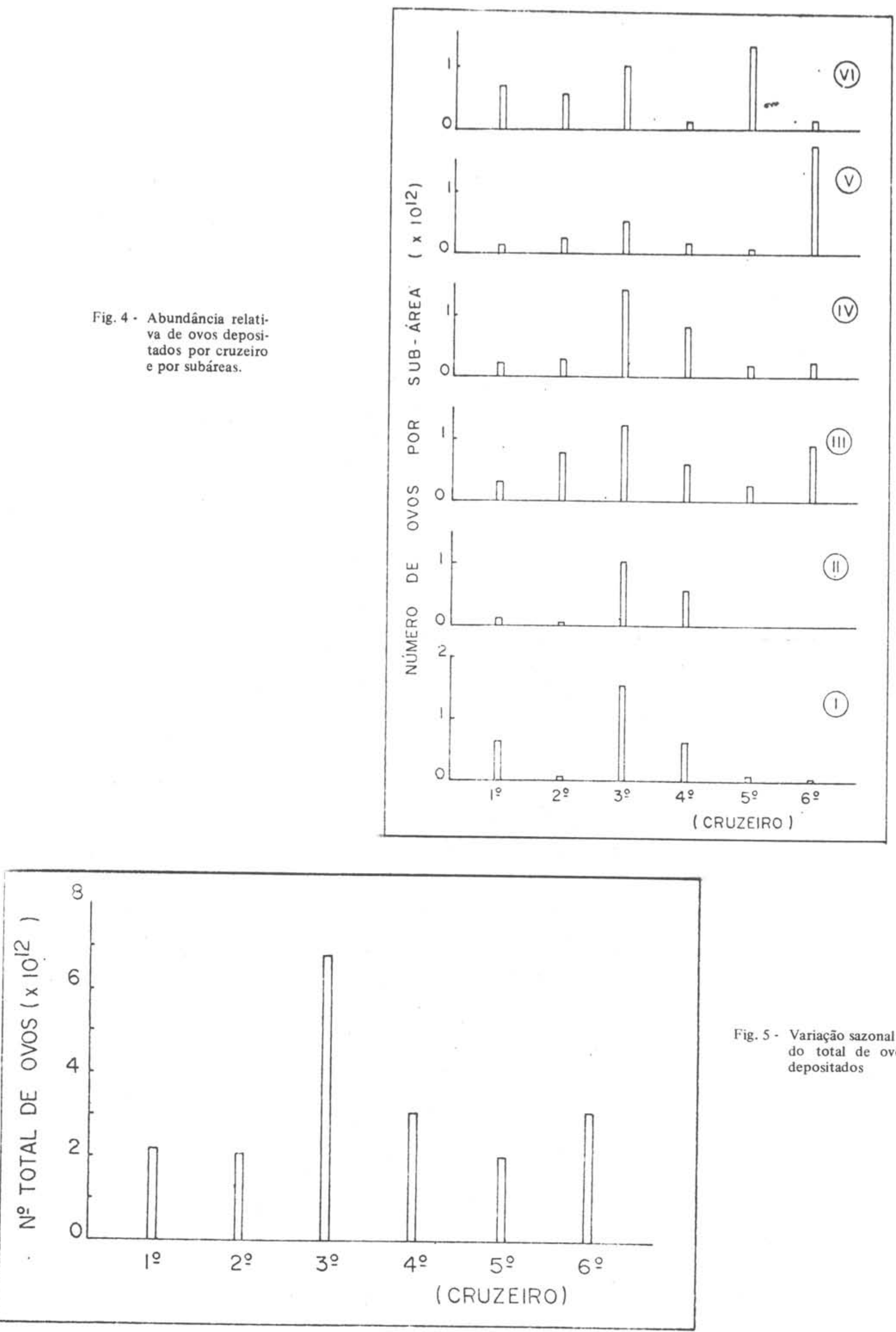

Fig. 5 - Variação sazonal do total de ovos depositados 


\section{Capturas do Peixe-Espada Adulto}

Na Figura 6, apresentamos a produção total de peixe-espada capturado no Brasil, onde podemos verificar que elas têm aumen. tado anuaimente, desde 1970.

Em termos regionais, o Estado do Rio de Janeiro, apresentou" um aumento de produção até o ano de 1970 mas, nos anos se. ruintes, após sofrer uma queda, elas tẻm oscilado entre 150 a 200
Toneladas anuass. No Estado de Sao raulo e de Santa Catarına, a producẩo tem aumentado consideravelmente, apesar de no Estado de São Paulo, durante os anos de 1972 e 1973, não ter apresentado uma boa produção. O mesmo não ocorreu no Éstado de Santa Catarina, onde o aumento foi gradativo de ano para ano, atingindo em 1976 a sua maior captura. No Estado do Rio Grande do Sul, a produção do peixe-espada é muito pequena, quando comparada com os ou. tros Estados, portanto, em 1974 a captura nos Estados de Säo Paulo e Santa Catarina, contribuiram com cerca de $50 \%$ da produção total pescada no sul do Brasil.

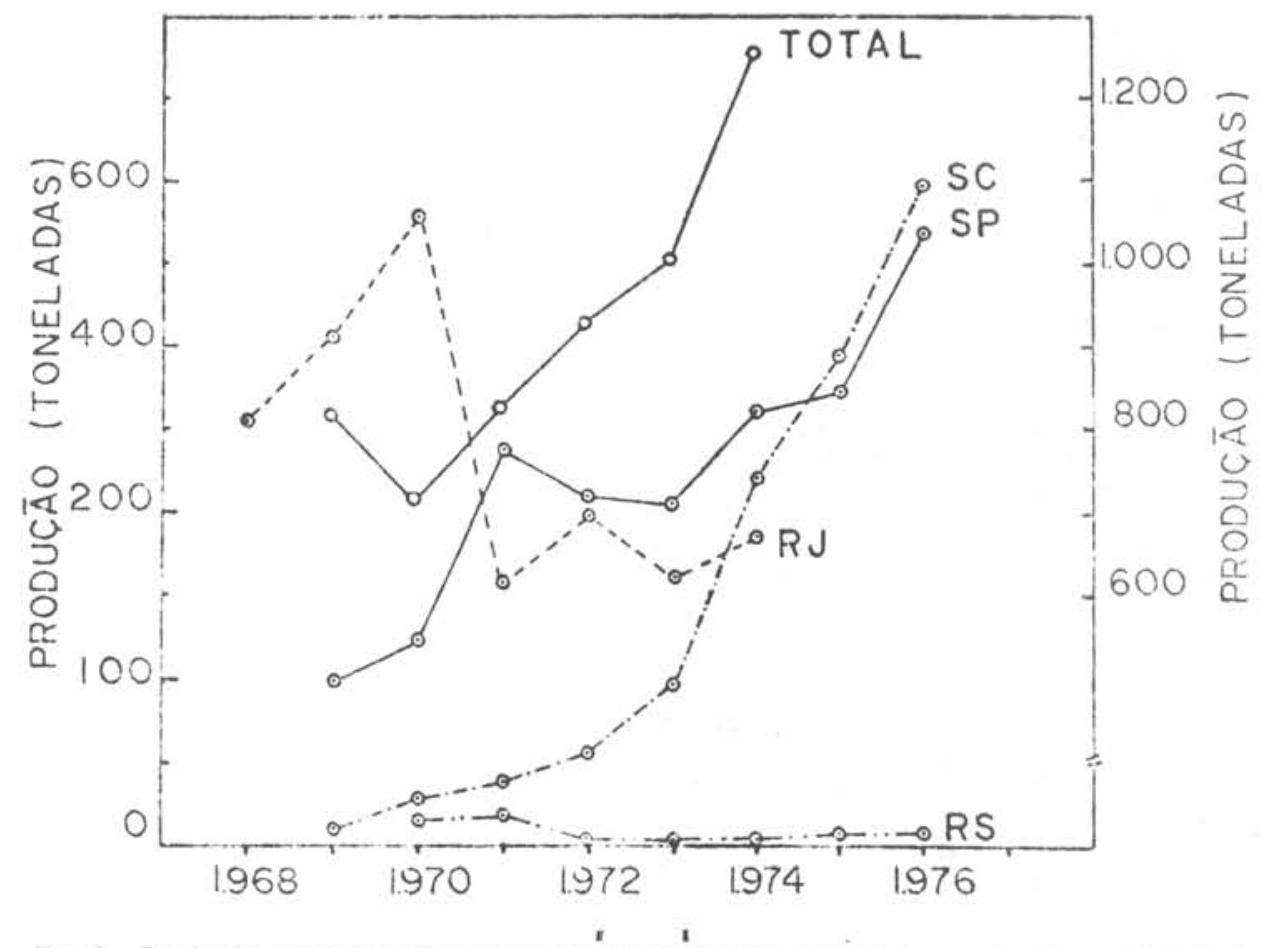

Fig. 6 - Produção total de peixe-espada no" Brasil (coluna a direita) e produção nos Estados (coluna a esquerda

uapturas de adultos foram obtidos do Boletim de Mercado Pesqueiro (PDP/SUDEPE, de 1968 à 1977).

\section{Sumário}

1 - De um modo geral, podemos supor que o peixe-espada desova o ano todo, com exceção na região sul, onde não foram assinaladas desovas no período de inverno, provavelmente devido à influência da corrente fria das Mal vinas, que durante esta época do ano atinge até a costa do Estado de Santa Catarina.

2 - A principal área de desova, localiza-se na região da tha de São Sebastião, tendo sido assinalada a sua ocorrência em cinco dos seis cruzeiros realizados.

3 - A temperatura na área de desovva variou entre $21,15^{\circ} \mathrm{C}$ e $26,29^{\circ} \mathrm{C}$, apresentando uma média de $24,09^{\circ} \mathrm{C}$. enquanto que a salinidade variou dentre $35,04 \%$ e $35,52 \%$ apresentando uma média de $35,31 \%$.

4 - As larvas do peixe-espada, ocorreram principalmente no $3^{\circ}$ cruzeiro, realizado em maio/76 (outono), coincidindo com a maior abundância de ovos.

5 - A estimativa do número total de ovos mostrou que as subáreas de Ilha Grande e Santa Catarina, foram as que contribuiram com maior porcentagem, coincidindo com a região onde ocorreu maior produção de adutos.

6 - Ocorreu um aumento anual na produção do peixe espada, principalmente nos Estados de São Paulo e Santa Catarina.

\section{Bibliografia}

MATSUURA, Y. 1971. Relatório preliminar sobre a distribuição de ovos e larvas de peixes nas águas da plataforma continental do Estado do Rio Grande do Sul. Contrçōes Inst. oceanogr. Univ. S Paulo, sér. Oceanogr. biol,. (25) : 23-30. ... 1977. O ciclo de vida da sardinha-verdadeira (In trodução à oceanografia pesqueira). Publção esp. Inst. oceanogr., S Paulo, (4): 1-146.

PDP/SUDEPE. 1968-1977. Boletim do mercado pesqueiro

PHONLOR, G. 1973. Estudo preliminar do ictioplâncton. Pro grama Rio Grande do Sul-II. Publção esp. Inst. oceanogr. S Paulo, (3, pt.1) : 427-464

TANAKA, S. 1973. Stock assessment by means of ichthyoplan

TSUKAHARA, H. 1961. Biology of the cutlassfish.

TANAKA, S. 1973. Stock assessment by means of ichthyoplan kton surveys. FAO Fish, tech. Pap., (122) : 33-51.

TSUKAHARA, H. 1961. Biology of the cutlassfish, Trichiurus lepturus Linnaeus. Part 1. Early life history. Contr. Dep. Fish. Fishery Res. Lab. Kyushu Univ.. (7): Rec. oceanogr. Wks Japan, spec. no., (5): 117-121

1962. Biology of the cutlassfish, Trichiunus lepturus Linnaeus. Part. 2. Age and growth. Contr. Dep. Fish. Fishery Res. Lah. Kyushu Univ., (8); Rec, oceanogr. Wks Japan, spec. no, (6): 57-64.

WEISS, G.; SOUZA, J. A. F. \& SANTOS, A. 1976. Contribuição ao conhecimento do ictioplâncton marinho da plataforma sul do Brasil. Atlântica, Rio Grande, 1 (1/2) : 7-78. 